\title{
Proposta de uma matriz de análise de estraté- gias sociotécnicas de visibilidade e legitimidade presentes em blogs corporativos
}

\author{
Elisangela Lasta* \\ Eugenia Mariano da Rocha Barichello**
}

\section{Resumo}

Os processos comunicacionais propostos pelos atores sociais na mídia digital implicam na sociotécnica relativa a essa mídia/blog corporativo. Essa dinâmica, no contexto da Comunicação Organizacional, se entrelaça a estratégias de visibilidade e de legitimidade. $\mathrm{O}$ estudo objetivou apresentar o desenvolvimento da matriz de análise de estratégias sociotécnicas de visibilidade e legitimidade presentes em blogs corporativos. A metodologia utilizou a pesquisa empírica mediada por computador (JOHNSON, 2010) a partir da observação encoberta e não participativa do campo de estudo e da triangulação de técnicas metodológicas com a matriz de tipificação de blogs (PRIMO, 2008a, 2008b, 2010) e a articulação entre teoria e dados empíricos. A matriz aqui proposta busca contribuir com a demanda de compreensão dos processos de Comunicação na dinâmica relativa à mídia digital/blog corporativo no âmbito estratégico.

Palavras-chave: Processos comunicacionais. Blog corporativo. Estratégias sociotécnicas. Visibilidade e legitimidade mediadas. Comunicação Organizacional.

\footnotetext{
"Professora substituta do Curso de Comunicação Social, Faculdade de Comunicação, Universidade Federal do Rio Grande do Sul (UFRGS). Doutoranda em Comunicação pela Universidade Federal de Santa Maria (UFSM), Santa Maria-RS, Brasil.E-mail: elisangela.lasta@gmail.com

** Professora e coordenadora do Programa de Pós-Graduação em Comunicação, Pró-Reitoria de Pós-Graduação e Pesquisa, Universidade Federal de Santa Maria (UFSM), Santa Maria-RS, Brasil. Doutora em Comunicação pela Universidade Federal do Rio de Janeiro (UFRJ).E-mail: eugeniamarianodarocha@gmail.com
} 


\section{Proposal of a matrix analysis of sociotechnical strategies of visibility and legitimacy present in corporate blogging Abstract}

The communication processes proposed by the social actors in the digital media imply the sociotechnical on this media/corporate blog. This dynamics, in the context of Organizational Communication, intertwines the strategies of visibility and legitimacy. The study aimed to introduce the development of the matrix analysis of sociotechnical strategies of visibility and legitimacy present in corporate blogging. The methodology used empirical research computer mediated (JOHNSON, 2010), starting from the covert observation and non-participatory in the field of study and methodological triangulation techniques with matrix to typifying blogs (PRIMO, 2008a, 2008b, 2010), and the relationship between theory and empirical data. The matrix proposed here aims to contribute to the demand for understanding of communication processes in the dynamics on the digital media/corporate blog in the strategic scope.

Keywords: Communication processes. Corporate blog. Sociotechnical strategies. Mediated visibility and legitimacy. Organizational Communication.

\section{Propuesta de una matriz de análisis de estrategias sociotécnicas de visibilidad y legitimidad presentes en los blogs corporativos Resumen}

Los procesos de Comunicación propuestos por los actores sociales en los medios digitales implica en la sociotécnica en este medio/blog corporativo. Esta dinámica, en el contexto de la Comunicación Organizacional, entrelaza las estrategias de visibilidad y legitimidad. El estudio tuvo como objetivo presentar el desarrollo de la matriz de análisis de estrategias sociotécnicas de visibilidad y legitimidad presentes en los blogs corporativos. La metodología utilizado de la investigación empírica mediada por ordenador (JOHNSON, 2010) desde el estudio de la observación de campo encubierta y no participativa y las técnicas metodológicas de triangulación con la matriz de clasificación de los blogs (PRIMO, 2008a, 2008b, 2010) y la articulación entre la teoría y los datos empíricos. La matriz que aquí se propone tiene como objetivo contribuir a la demanda de la comprensión de los procesos de Comunicación en la dinámica de los medios de Comunicación digitales/blog corporativo en el marco estratégico.

Palabras clave: Los procesos de comunicación. Blogs corporativos. Estrategias sociotécnicas. La visibilidad mediada y la legitimidad. La Comunicación Organizacional. 


\section{Introdução}

o estudarmos a temática da mídia digital, é importante
levar em consideração os aspectos sociotécnicos de cada
interface analisada, pois cada uma possui particularidades sociotécnicas que envolvem considerações quanto as suas potencialidades e limites, que terão reflexos nas ações praticadas nelas por múltiplos atores sociais presentes nessas interfaces. Partimos, portanto, inicialmente da compreensão do termo blog de acordo com Primo e Smaniotto (2006) que o entendem sob três aspectos: texto, programa e espaço. Porém, propomos neste estudo a conexão dessas três dimensões de modo a abranger o blog como mídia conforme o entendimento de mídia proposto por Sodré (2009), ou seja, uma ambiência com estrutura de códigos próprios, que envolve tanto a sociedade como as organizações. Acreditamos que a adoção do entendimento dos blogs a partir do conceito de mídia (SODRÉ, 2009) possibilita a conexão entre o texto, o programa e o espaço, pois a mídia, entendida como ambiência com estrutura de códigos próprios, traz esses três elementos constituintes do blog à discussão. Essa abordagem evita a redução da análise dos blogs somente ao seu aspecto textual, por exemplo, pois além desse elemento há o seu caráter tecnológico conjuntamente com as práticas conectivas dinamizadas pelos múltiplos atores sociais. Consequentemente, essa contextualização ampara-se nos pressupostos de que as estratégias de visibilidade articulam modos de ver/oferecem senhas de acesso (BARICHELLO, 2008) e as estratégias de legitimidade articulam explicações e justificações (BERGER; LUCKMANN, 1997), por meio do jeito próprio/particular de ver e fazer e de se posicionar (BALDISSERA, 2001). Por meio das escolhas/decisões, são potencializados certos elementos sociotécnicos em detrimento de outros, da mídia digital, fenômeno que pode ser comprovado a partir da observação de marcas/traços relativos à organização das ações empreendidas nos blogs corporativos presentes na blogosfera brasileira.

Por meio dessa articulação inserimos a problemática desta pesquisa ao indagar: como poderíamos pesquisar metodológica e 
empiricamente o fenômeno dos blogs corporativos a partir de sua concepção de mídia no contexto da Comunicação Organizacional que movimenta os conceitos de visibilidade e legitimidade? Visando contribuir com a elucidação dessa problemática desenvolvemos uma matriz de estratégias sociotécnicas de visibilidade e legitimidade para os blogs corporativos.

O estudo baseou-se na metodologia de pesquisa empírica mediada por computador, proposta por Johnson (2010), a partir da observação de campo e da triangulação de técnicas metodológicas. O campo do estudo foi composto pelo espaço online de 16 blogs corporativos, que foram selecionados por meio de critérios detalhados na primeira parte do artigo. A observação se deu a partir da elaboração de uma pauta de observação encoberta e não participativa do campo de estudo. Já o método da triangulação de técnicas metodológicas - que implica o uso de diversas técnicas na análise do corpus - propiciou-nos a utilização: a) da matriz de gêneros de blogs proposta por Primo (2008b) que categoriza os blogs em 16 gêneros ${ }^{1}$. Dentre os 16 gêneros classificados quatro foram considerados, neste estudo, como correspondentes aos blogs corporativos: organizacional autorreflexivo (O.A-R); organizacional informativo interno (O.I-I); organizacional informativo (O.I); e organizacional reflexivo (O.R), tipificados a partir dos perfis textuais; e a b) articulação entre teoria e dados empíricos.

O texto está subdividido em três partes: a primeira traz a estratégia metodológica utilizada para a presente pesquisa (JOHNSON, 2010), com a delimitação do campo de estudo e do corpus; a segunda aborda os procedimentos metodológicos relativos à observação encoberta e não participativa do campo de estudo, a matriz

\footnotetext{
${ }^{1}$ Os 16 gêneros de blogs (1 profissional auto reflexivo; 2 profissional informativo interno; 3 profissional informativo; 4 profissional reflexivo; 5 pessoal auto reflexivo; 6 pessoal informativo interno; 7 pessoal informativo; 8 pessoal reflexivo; 9 grupal auto reflexivo; 10 grupal informativo interno; 11 grupal informativo; 12 grupal reflexivo; 13 organizacional auto reflexivo; 14 organizacional informativo interno; 15 organizacional informativo; 16 organizacional reflexivo) estão descritos na versão hipertextual da matriz (PRIMO, 2008). Disponível em: http:// www6.ufrgs.br/limc/generos_blog.htm.
} 
de tipificação de gêneros de blogs (PRIMO, 2008a; 2008b; 2010) e a articulação entre teoria e dados empíricos; a terceira descreve e discute a construção de uma matriz de estratégias sociotécnicas de visibilidade e legitimidade para os blogs corporativos.

\section{Estratégia metodológica}

Este estudo tem como base a metodologia de pesquisa empírica mediada por computador, proposta por Johnson (2010), que inclui as técnicas de observação de campo - para a autora, os espaços online como os portais, websites, blogs, dentre outros, se tornam o "campo" a ser estudado - e a triangulação de técnicas metodológicas. No método da observação de campo, optamos pela observação encoberta e não participativa, pois nesse tipo de observação o pesquisador apenas observa o seu campo de estudo, sem que os sujeitos observados saibam que estão sendo estudados.

A delimitação do campo de estudo do espaço online dos blogs corporativos obedeceu aos seguintes critérios: a) blogs corporativos pertencentes a empresas presentes na listagem da Bolsa de Valores, Mercadorias e Futuros (BM\&FBOVESPA, 2009); b) blogs corporativos de médias-grandes empresas e grandes empresas de acordo com os critérios de classificação do Banco Nacional de Desenvolvimento Econômico e Social (BNDES); c) constituíremse em blogs externos e oficiais, agregados aos sites das empresas; portanto, reconhecidos pelas respectivas organizações; d) possuírem atualizações no ano de 2011; e) pertencentes à blogosfera brasileira; f) disponibilizados em língua portuguesa (Brasil).

Foram selecionados os posts de 16 blogs corporativos do campo de estudo, dos meses de janeiro, março e maio de 2011. O corpus foi composto por 353 posts em janeiro, 399 posts em março e 398 posts em maio, totalizando assim, 1.150 posts. A opção por esses meses deu-se em função de possuírem, em comum, 31 dias e por comporem o primeiro semestre do ano de 2011.

A estratégia metodológica permitiu o cruzamento dos dados obtidos com a metodologia de pesquisa empírica mediada por computador (JOHNSON, 2010) e os aspectos sociotécnicos par- 
ticulares da mídia digital blog corporativo. Esses estão demonstrados na Figura 1, Procedimentos metodológicos, na qual podemos visualizar o início do processo com a observação encoberta e não participativa do campo de estudo, seguida pelo uso da matriz de tipificação de blogs (PRIMO, 2008b) e, por fim, a articulação entre teoria e dados empíricos.

Figura 1 - Procedimentos metodológicos

$$
\begin{aligned}
& 1^{\circ} \text {. Observação encoberta e não participativa do } \\
& \text { campo de estudo; }
\end{aligned}
$$

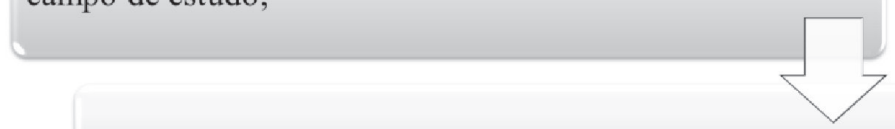

$2^{\circ}$. Matriz de tipificação de blogs proposta por Primo (2008b);

$3^{\circ}$. Articulação entre teoria e dados empíricos.

primeiro procedimento, observação encoberta e não participativa do campo de estudo, foi efetivado por meio da elaboração de um quadro com pautas, a serem observadas e documentadas, relativas aos blogs corporativos em seus aspectos de espaço e de programa. Os resultados desse procedimento permitiram a criação de um quadro panorâmico sobre esses elementos, correspondentes aos blogs corporativos das médias-grandes empresas e das grandes empresas. Já o segundo procedimento, que aplicou a matriz de tipificação de blogs, proposta por Primo (2008b) aos blogs do corpus de estudo, permitiu desvelar o aspecto relativo aos blogs como mídia: a relação entre blog e texto. Já o terceiro procedimento, articulação entre teoria e dados empíricos, permitiu a classificação dos blogs corporativos no que se refere às estratégias de visibilidade e legitimidade aos seus aspectos de mídia, isto é, como blog/ programa e blog/espaço. 


\section{Observação encoberta e não participativa do campo de estudo}

A observação de campo encoberta e não participativa baseou- se no Quadro 1 - Pautas para a análise de um blog, de Orihuela (2007, p.5-6). A partir dessas pautas, produzimos um quadro para a observação do campo de estudo (Quadro 1):

Quadro 1 - Pauta da observação encoberta e não participativa do campo de estudo.

\section{Média-Grande Empresa ou Grande Empresa}

1. Conteúdo contido na área de informações sobre o blog:

2. Ferramentas/botões de recomendação e aprovação de conteúdo:

3. Alojamento do blog:

Utiliza um domínio próprio ou um serviço de hospedagem?

4. Antiguidade e frequência das atualizações:

Desde quando há publicações no blog?

Qual a frequência das atualizações?

5. Política de links contextuais (links colocados no corpo do post):

Há a inclusão de links contextuais nos posts? Quais são os links?

6. Blogroll (lista de blogs):

7. Comentários e debates:

Há possibilidade de comentar no blog corporativo?

Há comentários no blog corporativo?

8. Inserção de imagens e vídeos:

Imagens?

Vídeos?

Fonte: Adaptado pelas autoras a partir de Orihuela (2007)

A partir do preenchimento do Quadro 1, elaboramos um quadro panorâmico dos blogs corporativos no que se refere ao uso/apropriação dos elementos sociotécnicos correspondentes aos aspectos dos blogs como mídia (programa/espaço).

Buscamos a quantificação e qualificação do campo de estudo, considerando sempre as medidas de posição e de dispersão, ou variabilidade como: a média, o desvio padrão, o coeficiente de variação de cada empresa e no total do campo de estudo. A partir das médias, obtivemos as medidas de posições estáveis e instáveis, porém, a média por si só não nos permite qualificar 
os dados. Para tanto, utilizamos a média e o desvio padrão para chegarmos ao coeficiente de variação $(\mathrm{CV})$, que nos permite comparar o grau de concentração em torno das médias. Os conjuntos dos dados foram classificados de acordo com o $\mathrm{CV} \leq$ 30 , grupo homogêneo em relação às médias; e $\mathrm{CV} \geq 30$, grupo heterogêneo em relação às médias. Essas medidas, de posição e de dispersão ou variabilidade, conferem propriedade quanto à regularidade e à coerência relativas aos usos e apropriações realizadas nos blogs corporativos do campo de estudo, consequentemente às inferências.

\section{Matriz de tipificação de blogs proposta por Primo (2008a; 2008b; 20I0)}

Primo (2008a), ao estudar o fenômeno dos blogs, constatou que os modelos existentes para defini-los eram reducionistas, já que os blogs apresentam estilos e objetivos diversos. Ao desenvolver essa perspectiva acerca dos diferentes gêneros discursivos contidos nos blogs e sob o aspecto da mudança contínua encontrada neles, Primo (2008b) apresentou um método que visava tipificar os blogs em gêneros discursivos respeitando suas diferenças. Criou uma matriz de tipificação de blogs que permite categorizar os blogs de acordo com os 16 gêneros, a partir das relações internas e das questões textuais.

Os 16 gêneros de blogs possuem descrição específica para cada um. Na matriz de tipificação encontramos os tipos de blogs classificados como: 1) profissional (considerados individuais); 2) pessoal (considerados individuais); 3) grupal (considerados coletivos); e 4) organizacional (considerados coletivos). Cruzando com essa classificação, o autor discute os perfis organizando-os em: autor reflexivo; informativo interno; informativo e reflexivo. Conjuntamente, ele verifica se os blogs possuem interações formalizadas ou interações cotidianas e, por fim, se são de reflexão ou de relato. $O$ modelo da matriz de tipificação de blogs utilizada nesse estudo está exposto na figura 2. 
Figura 2 - Matriz para tipificação de blogs.

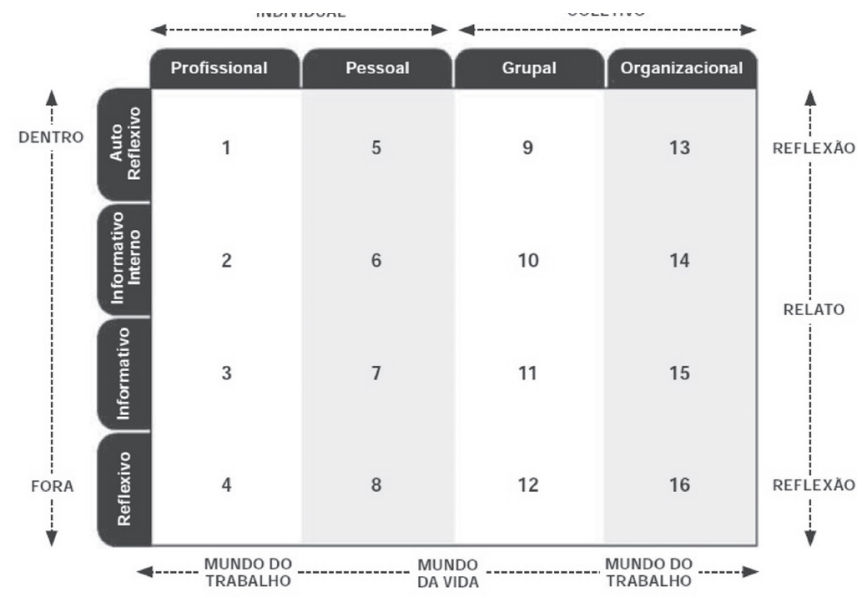

Fonte: Primo (2010)

Porém, nesta pesquisa nos deteremos somente aos gêneros 13, 14,15 e 16 da matriz por serem relativos aos blogs organizacionais, ou seja, aos blogs corporativos:

No número 13 (organizacional auto reflexivo): "Posts neste gênero de blog coletivo refletem sobre as atividades da organização, discutindo a força e riscos de projetos em andamento ou dos serviços e bens que oferecem" (PRIMO, 2008b, p.10). No número 14 (organizacional informativo interno): "[...] foca-se na divulgação de seus produtos e serviços, bem como das conquistas alcançadas (prêmios, crescimento, aquisições, etc.). Para esta finalidade, o blog/espaço converte-se em uma central de releases digitais" (PRIMO, 2008b, p.10-11). E no número 15 (organizacional informativo): "Este gênero de blog serve para registro de informações sobre o segmento de atuação da organização, sem que ela manifeste seu parecer sobre os fatos" (PRIMO, 2008b, p. 11). Já no número 16 (organizacional reflexivo): "É através deste blog coletivo que uma organização manifesta suas opiniões sobre os temas de seu interesse" (PRIMO, 2008a, p.12).

O número 13, Organizacional Auto reflexivo (O.A-R) e o 16, Organizacional Reflexivo (O.R), implicam na dimensão da 
reflexão que é entendida como: "Ponderações, análises críticas e opiniões [...]. Mesmo que descrições e resenhas sejam feitas, elas são acompanhadas de opiniões e juízos [...]"2. Já os gêneros 14, Organizacional Informativo-Interno (O.I-I) e 15, Organizacional Informativo (O.I), implicam na dimensão de relato: "Os posts classificados nesta dimensão buscam apenas fazer uma exposição objetiva, desprovida de qualquer julgamento crítico"3.

A metodologia aqui proposta utilizou esses gêneros organizacionais da matriz de Primo (2008b). Essa matriz de tipificação foi utilizada como fundamentação argumentativa na análise dos posts, de acordo com as descrições contidas nela, para chegarmos ao entendimento acerca dos gêneros, ou seja, a análise de discurso está implicitamente convocada. Como essa matriz foi criada e fundamentada em gêneros discursivos, com o intuito de servir como método para identificação de gêneros de blogs, não cabe a este estudo refazer as proposições dos gêneros discursivos nela propostos. A análise foi construída, deste modo, a partir da identificação rigorosa das marcas e características atribuídas aos posts descritas na matriz.

Para tipificar como blog corporativo Organizacional Autorreflexivo (O.A-R), buscamos marcas/características de reflexão sobre atividade da organização, discussão acerca da força e risco de projetos em andamento ou de serviços e produtos nos posts. Exemplo 1:

[...] pretende expor de forma mais clara e intuitiva a proposta da Coleção Portobello 2011, que, em linhas gerais, propõe uma maior integração entre o homem e o ambiente natural. [...] a Portobello vai lançar o primeiro aplicativo para iPad desenvolvido por uma empresa do segmento. $\mathrm{O}$ aplicativo, chamado de iPortobello, é a evolução dos tradicionais catálogos de lançamentos de produtos impressos, unindo em uma mesma plataforma conteúdos de texto, imagem, som e vídeo com muita interatividade. [...] O aplicativo é uma das muitas estratégias digitais que a Portobello está implantando neste ano. A empresa vai ampliar seus canais de Comunicação e o relacionamento na internet de forma a tornar-se a mais interativa do segmento (PORTOBELLO, 2011).

\footnotetext{
${ }^{2}$ Versão hipertextual da matriz (Primo, 2008). Disponível em: http://www6.ufrgs. br/limc/generos_blog.htm.

${ }^{3}$ Versão hipertextual da matriz (Primo, 2008). Disponível em: http://www6.ufrgs. br/limc/generos_blog.htm.
} 
No exemplo 1, podemos observar que no post há reflexão sobre o projeto de estratégia digital da Portobello, que está sendo implantado, e é discutido o projeto em seus aspectos positivos, detalhando-o para os leitores.

Para tipificar como blog corporativo Organizacional Informativo-Interno (O.I-I), buscamos marcas/características de divulgação dos seus produtos, serviços, conquistas, prêmios, crescimento e aquisições, ou seja, questões que envolvam a organização nos posts. Exemplo 2:

[...] saiba mais sobre o nosso aplicativo TAM Mobile. Você pode visualizar as melhores ofertas de passagens, os roteiros TAM Viagens e as condições especiais para resgatar os seus pontos do programa TAM Fidelidade. E tudo isso de onde você estiver, através do seu Blackberry. Quer evitar fila? Com o aplicativo TAM Mobile você também pode realizar o check-in por meio do seu celular. [...] Por enquanto, esse serviço está disponível apenas nos voos de Ribeirão Preto a Congonhas e São José do Rio Preto a São Paulo e Cuiabá. Ele está disponível para download gratuito na APP World [...] (TAM, 2011).

No exemplo 2, o post divulga informações sobre um novo serviço que a TAM está disponibilizando aos seus clientes. Diferentemente do exemplo 1, em que há a discussão a partir da força que a Portobello acredita ter o seu projeto de estratégia, no exemplo 2 temos um post voltado para a divulgação de um serviço da empresa sem opiniões de juízo.

Para tipificar como blog corporativo Organizacional Informativo (O.I) buscamos marcas/características de registro de informações sobre o segmento de atuação da organização sem manifestar sua opinião sobre o fato nos posts. Exemplo 3:

Para comemorar o Dia Mundial da Água, a rede BBC publicou fotografias que mostram a busca pela água potável em diversos países. Veja: - Na aldeia Dan Mairo, África Subsaariana, mulheres e crianças recolhem água do poço e fazem o armazenamento em baldes e garrafões: - Mulher questiona a qualidade da água, em protesto na Rússia: - Em Rajastán, na Índia, a população caminha $5 \mathrm{Km}$ diariamente para encher seus baldes: - Na Síria, a água das chuvas é transportada em burros e outros animais: - A água é vendida por US\$ 0,76 na China: - No Brasil, duas mulheres compram garrafinhas de água por $\mathrm{R} \$ 6$, na praia de Ipanema: Para ver mais detalhes destas e de outras imagens, clique [...] (AMPLA , 2011). 
No exemplo 3, o post da empresa Ampla Energia e Serviços S.A. transcreve no dia mundial da água uma matéria da BBC sem manifestar sua opinião sobre o fato. Registra, assim, uma informação que diz respeito a elementos do seu segmento de atuação sem manifestar sua opinião.

Para tipificar como blog corporativo Organizacional Reflexivo (O.R), buscamos marcas/características de manifestação de opinião da organização sobre temas de seu interesse nos posts. Exemplo 4:

[...] Kourt é cheia de estilo e ultimamente tem acertado bastante nas escolhas de looks. Nós amamos esta combinação dela, porque apesar de ser simples, é super elegante e a bolsa de animal print dá um toque moderno e fashion. Seja para trabalhar ou dar aquela voltinha no domingão, é uma escolha certeira, linda e confortável [...] (RESTOQUE , 2011).

Já no exemplo 4, correspondente ao blog corporativo da Restoque Comércio e Confecções de Roupas S.A., há a manifestação da opinião da empresa, em quase sua totalidade, a partir do uso de adjetivos.

Essa matriz permite ao pesquisador identificar os blogs de acordo com seus 16 gêneros no que diz respeito ao perfil textual. Ela contribui para o mapeamento dos blogs corporativos em sua dimensão de mídia/texto. Entretanto, não nos permite descobrir as peculiaridades dos blogs no que diz respeito ao perfil textual sob seu aspecto estratégico.

Os gêneros textuais relativos aos blogs corporativos das Médias-Grandes Empresas e das Grandes Empresas refletem não somente as ocorrências dos gêneros de blogs sob seus aspectos textuais nos respectivos espaços dos blogs corporativos como também podem nos inserir na esfera estratégica, consequentemente podem transparecer o posicionamento dessas empresas no que se refere sua inserção nas ambiências da mídia digital frente a outrem. Acreditamos que a consistência e a regularidade referentes aos gêneros nas postagens qualificam o blog corporativo quanto à coerência da sua proposta. Ou seja, o blog corporativo que apresenta somente maior percentual em um dos gêneros não pode ser qualificado em relação aos demais. Até porque mesclar os quatro tipos de gêneros 
nas postagens se o for de forma consistente o será estratégico no contexto da Comunicação Organizacional.

\section{Articulação entre teoria e dados empíricos}

A partir do mapeamento e da tipificação dos blogs corporativos das Médias-Grandes Empresas e Grandes Empresas do campo de estudo, procuramos compreender os blogs em seus aspectos de programa, de espaço e de texto. Já na articulação entre a teoria e os resultados dos dados empíricos deste estudo, representada na Figura 3, foi buscada a conexão entre o blog/texto, o blog/ programa e o blog/espaço.

Figura 3 - Articulação entre teoria e dados empíricos

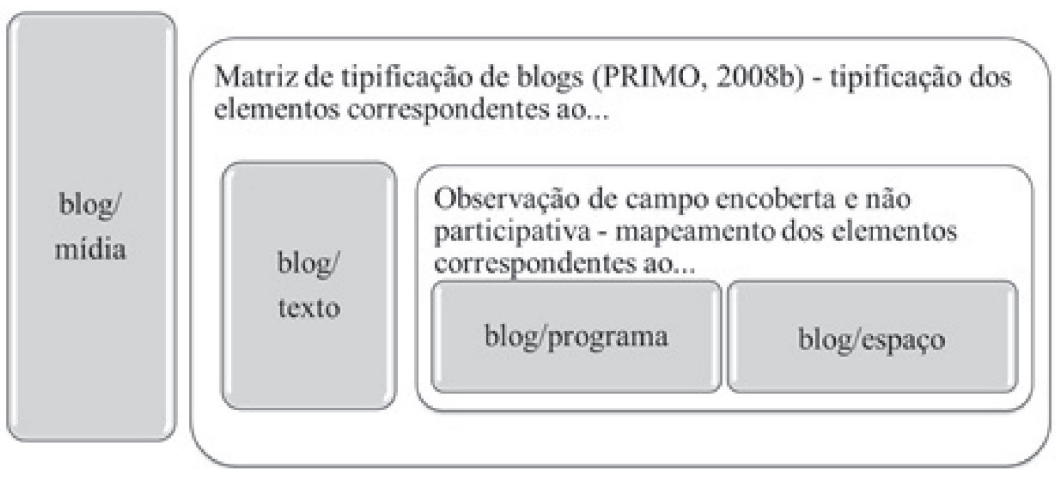

Ao considerarmos o blog como mídia o entendemos como ambiência, com estrutura de códigos próprios e, consideramos, portanto, os elementos do blog/programa, do blog/espaço e do blog/texto constituintes na discussão e interpretação dos dados, visando o desenvolvimento da matriz de estratégias sociotécnicas de visibilidade e legitimidade para os blogs corporativos.

A articulação entre a teoria e os dados empíricos ocorreu a partir das questões teóricas, relativas aos aspectos sociotécnicos dos blogs que envolviam questões referentes aos processos de vi- 
sibilidade e legitimidade, ou seja, considerando que as estratégias sociotécnicas de visibilidade (articulam modos de ver/oferecem senhas de acesso a partir da sociotécnica da mídia digital blog) e as estratégias sociotécnicas de legitimidade (articulam explicações e justificações a partir da sociotécnica da mídia digital blog).

A dinâmica de articulação entre teoria e dados se deu por meio dos seguintes elementos:

a) Área sobre: apropriação e uso da área "sobre" implica no "fazer conhecer" o posicionamento da empresa sobre seu blog corporativo a outrem. Deixa explicita a 'explicação' e a 'justificação' do por que da apropriação e uso dessa mídia digital. Essa postura tenderá a refletir no reconhecimento.

b) Ferramenta botão de recomendação/aprovação de conteúdo: apropriação/uso das ferramentas/botões de recomendação e aprovação de conteúdos implica na divulgação de conteúdo do blog corporativo (permalinks) no Facebook e Twitter de outrem. Essa dinâmica tenderá a refletir no reconhecimento nas estratégias sociotécnicas de visibilidade. Como também implica no reconhecimento do conteúdo do blog corporativo via aprovação e recomendação também é provável que mostre indícios de reconhecimento de estratégias sociotécnicas de legitimidade.

c) Frequência de postagem: a frequência das postagens implica na ordem de posicionamento dos blogs nos buscadores. Pois, em função de serem atualizados mais frequentemente do que sites institucionais acabam por serem encontrados facilmente pelos mecanismos de busca. Essa dinâmica poderá evidenciar estratégias sociotécnicas de visibilidade.

d) Política de links: o uso dos hiperlinks de referência a outrem implica na possibilidade de vir a ser linkado por outros blogs e, assim, estar nos primeiros lugares dos buscadores. Essa dinâmica tenderá a desvelar o reconhecimento de estratégias sociotécnicas de visibilidade. E, também, implica na transcendência dos limites do seu espaço (blog) e o insere em uma rede de vínculos e relações (blogosfera); constrói uma rede de relações, ou seja, essa dinâmica 
tenderá a mostrar pistas do relacionamento que impliquem em estratégias sociotécnicas de legitimidade.

e) Blogroll: lista de blogs lidos e/ou recomendados pelo blog corporativo. A consequência, de linkar outros blogs é de que pode vir a ser linkado e assim estar nos primeiros lugares dos buscadores. Essa postura tenderá a refletir o relacionamento nas estratégias sociotécnicas de visibilidade. Além disso, constrói uma rede de relações com outros blogs por meio de/dentro do seu espaço (blog). Essa dinâmica tenderá a mostrar indicadores de estratégias sociotécnicas de legitimidade.

f) Caixa para comentários: como os comentários são rastreados pelos mecanismos dos buscadores, cada novo comentário equivale a uma nova atualização. Essa dinâmica tenderá a refletir no relacionamento nas estratégias sociotécnicas de visibilidade, como também, se torna um convite para a conversação com os interagentes no seu espaço. Reflete o posicionamento de abertura para o diálogo nessa ambiência, ou seja, espaço de negociação. Essa dinâmica tenderá a demonstrar o relacionamento da empresa que inclua estratégias sociotécnicas de legitimidade.

Essas articulações teóricas entre as conexões blog/programa e blog/espaço e as discussões acerca da visibilidade e legitimidade na sociedade midiatizada permitiram os atrelamentos necessários para a elaboração da matriz de estratégias sociotécnicas de visibilidade e legitimidade para os blogs corporativos a ser detalhada a seguir.

\section{Proposta de uma da matriz de análise de estratégias sociotécnicas de visibilidade e legitimidade para blogs corporativos}

A matriz de estratégias sociotécnicas de visibilidade e legitimidade para análise de blogs corporativos foca a dinâmica envolvida no processo de apropriação e uso dos elementos sociotécnicos nos blogs corporativos. Isto é, seu funcionamento parte dos mecanismos tecnológicos, da construção de seus significados e da dinâmica que geram. 
Figura 4 - Matriz de estratégias sociotécnicas de visibilidade e legitimidade para os blogs corporativos

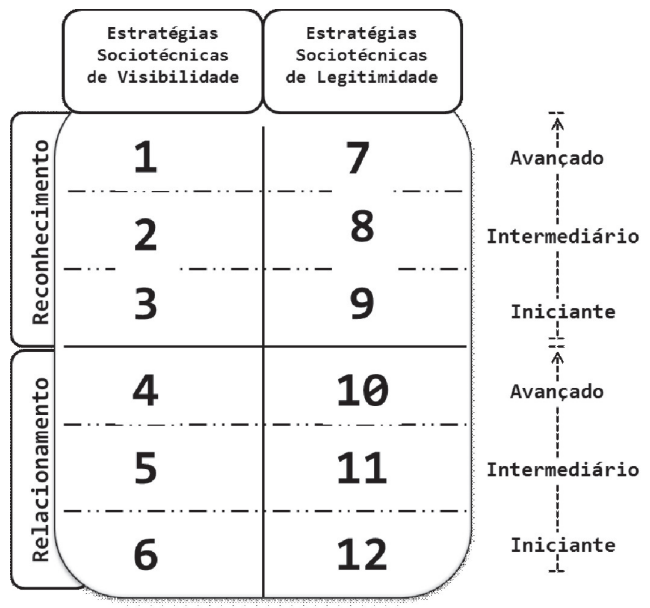

Essa matriz pressupõe que uso/apropriação do blog corporativo, entendido como mídia, tem em seu âmago as proposições tanto de reconhecimento como de relacionamento. Isto é, ele pode ser usado/apropriado para ambos os posicionamentos, ou somente para um deles, mesmo que o potencial sociotécnico abarque tanto o posicionamento de reconhecimento como de relacionamento, cabe à organização/instituição/empresa defini-los. E, portanto, na matriz encontramos os posicionamentos de reconhecimento e relacionamento e seus níveis.

Ao trazermos os entendimentos desta proposta de matriz de análise, quanto ao reconhecimento e ao relacionamento, cabe agora esclarecê-los quanto à compreensão de posicionamento das estratégias sociotécnicas de visibilidade e legitimidade para os blogs corporativos (dispostos no lado esquerdo da matriz) e estabelecermos as conexões com os autores que formam a base teórica desta proposta:

- Os números 1, 2, 3, localizados no lado esquerdo da matriz, são relacionados ao reconhecimento, ou seja, propõem que o protagonista comunicante e o interagente são tanto reconhecidos como são reconhecedores (RICOEUR, 2006); ou seja, essas dinâmicas 
refletem na conquista de um olhar (outrem) que lhe proporcione visibilidade (BRUNO; PEDRO, 2004).

- Os números 4, 5, 6, também dispostos no lado esquerdo da matriz, propõem a relação com outrem (FRANÇA, 2009). Pois, mostram estratégias que objetivam ser lidas, escutadas e vistas e a ação de referenciar equivale à proposição/busca de estabelecer relação com outrem (ESTALELLA, 2005). Refletem a visão da web de acordo com os olhos dos serviços de busca.

- Os números 7, 8, 9, presentes no lado direito da matriz, propõem a visualização das estratégias que traduzem a luta pelo reconhecimento de si por outrem (RICOEUR, 2006) a partir da formação de seus repertórios (explicar e justificar) as suas existências perante outrem (BARICHELLO, 2008). A legitimidade está ligada ao processo pelo qual um corpo de conhecimento chega a ser socialmente estabelecido como realidade, ou seja, reconhecido (BERGER; LUCKMANN, 1997).

- E os números 10, 11, 12, dispostos no lado direito da matriz, referem-se às estratégias sociotécnicas que propõem o estabelecimento de vínculos oficiais que podem ser permanentes ou não (FRANÇA, 2009), visto que objetivam a legitimidade, ou seja, a qualidade de ser considerado legítimo por outrem (DUPAS, 2005).

A matriz de estratégias sociotécnicas, de visibilidade e legitimidade para os blogs corporativos, é posta em funcionamento a partir dos tensionamentos relativos aos elementos sociotécnicos do blog/ mídia - programa e espaço - (contidos nas proposições a, b, c, d, e, f) articulados a compreensão acerca da visibilidade e da legitimidade nesse contexto e rearticulado com a proposta de posicionamento (reconhecimento e relacionamento) os quais podem ser classificados em três níveis a partir da utilização da matriz: avançado, intermediário e iniciante. Procurando, dessa forma, contemplar também as tensões e possibilidades combinatórias presentes nos fluxos sociotécnicos da rede e suas possíveis estratégias.

\section{Considerações pontuais}

A resposta à problemática - como poderíamos pesquisar metodológica e empiricamente o fenômeno dos blogs corporativos a 
partir de sua concepção de mídia no contexto da Comunicação Organizacional que movimenta com os conceitos de visibilidade e legitimidade? - foi alcançada por meio dos procedimentos metodológicos (figura 1) que nos permitiu estudar o blog entendido como mídia ao tratar do blog/programa e espaço por meio de uma observação encoberta e não participativa do campo de estudo que possibilitou a coleta e visualização dos elementos sociotécnicos (blog/programa) apropriados/utilizados no blog/espaço; já a partir da matriz de Primo (2008a, 2008b, 2010) foi possível analisar o blog sob seu aspecto textual; e, por fim, o aprofundamento do estudo do fenômeno dos blogs corporativos a partir de contextualização com as noções de visibilidade e legitimidade no âmbito estratégico relativo aos aspectos do blog/programa e espaço a articulação entre teoria e dados empíricos que nos levou a construção da matriz de estratégias sociotécnicas de visibilidade e legitimidade para os blogs corporativos.

Por meio desses procedimentos, o blog foi compreendido e pesquisado metodológica e empiricamente como mídia, isto é, nos seus aspectos de programa, espaço e texto, entrelaçado com as potencialidades estratégicas de ver e ser visto e de explicar e justificar na ambiência digital. Como existe uma seleção/escolha/ decisão prévia e articulada do que será visível e do que será explicado e justificado a outrem/alteridade, logo, esse movimento pode ser compreendido como estratégico, e vincula as noções de visibilidade e legitimidade à Comunicação Organizacional na mídia digital/blog. Por conseguinte, as organizações/instituições/ empresas, ao promoverem essas escolhas em função das proposições em relação aos elementos sociotécnicos dos blogs corporativos como mídia, geram a repercussão e a potencialização de certos elementos sociotécnicos em detrimento de outros. Ações essas que, consequentemente, refletirão o posicionamento estratégico de visibilidade e legitimidade das organizações/instituições/empresas, frente a outrem, nos seus respectivos blogs corporativos, os quais podem ou não acolhê-las.

Esse cenário é modelado e remodelado constantemente pelas organizações/ empresas/instituição que usam/se apropriam dos 
blogs. Isto é, o cenário é constantemente alterado, aspecto esse que possibilita aos estudiosos a realização de pesquisas visando à observação do avanço ou retrocesso quanto ao quadro de estratégias no contexto da Comunicação Organizacional na mídia digital/ blog por meio da aplicação dessa matriz desenvolvida. No centro dessas dinâmicas, que envolvem a visibilidade e a legitimidade, no contexto das organizações e/ou instituições, está inscrita a área de relações públicas. Pois, pode-se deduzir que tanto as decisões da organização como as de outrem estão intrinsecamente ligadas aos processos de visibilidade e legitimidade. Entretanto, a proposta da matriz se concentra na produção, deixando a dinâmica da recepção para futuras pesquisas ao relacionar a essa contextualização o método da análise das redes sociais (ARS) combinado com a análise de conteúdo.

\section{Referências}

AMPLA ENERGIA E SERVIÇOS S. A. (2011). Disponível em: < http://conscienciaampla. wordpress.com/2011/03/22/ fotos-agua $>$. Acesso em: 08 mar. 2011.

BALDISSERA, Rudimar. Estratégia, Comunicação e Relações Públicas. In: XXIV CONGRESSO BRASILEIRO DA COMUNICAÇÃ̃O, setembro 2001, Mato Grosso do Sul. Anais, Campo Grande, Intercom, 2001. p.1-11.

BARICHELLO, Eugenia M.da Rocha. Apontamentos em torno da visibilidade e da lógica de legitimação das instituições na sociedade midiatizada. In: DUARTE, Maria Elizabeth Bastos; CASTRO, Maria Lilia Dias de (Orgs.). Em torno das mídias. Porto Alegre: Sulina, 2008. p. 237-49.

BERGER, Peter; LUCKMANN, Thomas. A construção social da realidade: tratado de sociologia do conhecimento. 14. ed. Petrópolis: Vozes, 1997.

BM\&FBOVESPA. Como e por que tornar-se uma companhia aberta utilizando o mercado de capitais para crescer. São Paulo: BM\&FBOVESPA, outubro de 2009. Disponível em: <http://www.bmfbovespa.com.br/empresas/download/ guiaaber.pdf $>$. Acesso em: 16 abril 2011.

BRUNO, Fernanda; PEDRO, Rosa. Entre aparecer e ser: tecnologia, espetáculo e subjetividade contemporânea. Intexto, Porto Alegre, v.2, n.11, jul./dez., p.1-6, 2004. 
DUPAS, Gilberto. Atores e poderes na nova ordem global: assimetrias, instabilidade e imperativos de legitimação. São Paulo: UNESP, 2005.

ESTALELLA, Adolfo. Anatomía de los blogs. La jerarquía de lo visible. Telos -Cuadernos de Comunicación, Tecnología y Sociedad, n.65, p. 119-26, 2005 .

FRANÇA, Fábio. Gestão de relacionamentos corporativos. In: FERRARI, Maria A.; FRANÇA, Fábio; GRUNIG, James (Orgs.). Relações públicas: teoria, contexto e relacionamento. São Caetano do Sul: Difusão, 2009. p. 209 -69.

JOHNSON, Telma. Pesquisa social mediada por computador: questões, metodologias e técnicas qualitativas. Rio de Janeiro: E-papers, 2010.

ORIHUELA, José Luis. Blogs e blogosfera: o meio e a comunidade. In: ORDUÑA, Octavio I. Rojas. et al (Orgs.). Blogs: revolucionando os meios de Comunicação. São Paulo: Cengage Learning, 2007. p. 1-20.

PORTOBELLO S.A. Portobello transmite desfile da coleção 2011 via twitcam. Disponível em: < http://www.portobello.com.br/blog/2011/03/18/portobello-transmite-desfile-da-colecao-2011-via-twitcam/>. Acesso em: 08 mar. 2011.

PRIMO, Alex. Os blogs não são diários pessoais online: matriz para a tipificação da blogosfera. Revista FAMECOS: Revista do Programa de Pós-Graduação em Comunicação, Porto Alegre, n. 36, p. 122-128, ago. 2008a.

. Blogs e seus gêneros: avaliação estatística dos 50 blogs mais populares em língua portuguesa. In: Anais do XXXI CONGRESSO BRASILEIRO DE CIÊNCIAS DA COMUNICAÇÃO. Natal/RN, set. 2008b. p. 1-14.

. Blogs e seus gêneros: avaliação estatística dos 50 blogs mais populares em língua portuguesa. Revista Matrizes: Revista do Programa de Pós-Graduação da ECA-USP, São Paulo, a. 4, n.1, jul./dez., 2010. p. 129 -47.

RESTOQUE COMÉRCIO E CONFECÇÕES DE ROUPAS S.A. (2011). Disponível em: < http://www.lelis.com.br/lelisblog/estilo-kourtney-kardashian/>. Acesso em: 08 mar. 2011.

RICOEUR, Paul. Percurso do reconhecimento. São Paulo: Loyola, 2006.

TAM S.A. (2011). Esteja onde estiver, saiba de todas as nossas ofertas. Baixe nosso aplicativo para Blackberry. Disponível em: < http://blog.tam.com. br/2011/03/esteja-onde-estiver-saiba-de-todas-as-nossas-ofertas-baixe-nosso-aplicativo-para-blackberry/>. Acesso em: 08 mar. 2011.

Recebido: 04/12/2012 Aceito: 04/04/2013 